\title{
Mediterranean diet and polyamine intake: possible contribution of increased polyamine intake to inhibition of age-associated disease
}

This article was published in the following Dove Press journal:

Nutrition and Dietary Supplements

15 December 2010

Number of times this article has been viewed

\author{
Phan Nguyen Thanh Binh' \\ Kuniyasu Soda ${ }^{2}$ \\ Masanobu Kawakami ${ }^{3}$ \\ 'Department of Food and Nutrition, \\ Japan Women's University, Tokyo, \\ Japan; ${ }^{2}$ Cardiovascular Research \\ Institute, ${ }^{3}$ Department of Internal \\ Medicine, Saitama Medical Center, \\ Jichi Medical University, Saitama, Japan
}

\begin{abstract}
The Mediterranean diet is a dietary pattern associated with increased longevity, and has been shown to have anti-inflammatory properties. Based on the findings that natural polyamines are strong anti-inflammatory substances, we have found that continuous and increased polyamine intake prolongs murine lifespan. Because polyamines are contained in most foods in widely varying concentrations, we sought epidemiologic evidence that supports an association between the Mediterranean diet and increased polyamine intake. The amounts of food supply in 49 European and other Western countries in 2005 were collected from the United Nations database, and the amount of food polyamine was estimated using polyamine concentrations in foods from published sources. The Mediterranean diet pattern was characteristically observed in Mediterranean countries. For all 49 countries and for foods such as olive oil (Spearman $r=0.602)$, fruit $(r=0.804)$, fruit and vegetables $(r=0.611)$, seafood $(r=0.461)$, and cheese $(r=0.411)$, the ratios of the amounts of these foods to total calories consumed were all positively associated $(P<0.05)$ with the amount of polyamine per calorie. Legumes per calorie $(r=0.379)$, wine per calorie $(r=0.285)$, and the amount of seafood and poultry meat relative to red meat $(r=0.313)$ had a trend of positive association with the amount of polyamine per calorie $(P<0.05)$, while several foods in the non-Mediterranean diet group had a trend of no or negative association. Food polyamines are absorbed quickly from the intestinal lumen, and long-term increased polyamine intake increases blood polyamine concentration. The present findings, together with previous studies on polyamines, indicate a possible role for the food polyamines that are abundant in the Mediterranean diet in prolonging human life.
\end{abstract}

Keywords: Mediterranean diet, polyamine, longevity, age-associated diseases

\section{Introduction}

The phrase "Mediterranean diet" reflects the dietary patterns characteristic of several countries in the Mediterranean Basin. In spite of the relatively high amount of fat consumed in Mediterranean countries, individuals living in these countries have far lower rates of cardiovascular disease than do those living in the surrounding European countries and the US, where similar levels of fat are consumed. A large number of epidemiologic studies, as well as several interventional studies, have shown that the Mediterranean diet pattern is closely associated with prolonged lifespan and decreased mortality due to chronic age-associated health deterioration. ${ }^{1-6}$

The principal components of the Mediterranean diet pattern include olive oil (the principal source of fat), high consumption of legumes, fruit, and vegetables, with moderate consumption of dairy products (mostly as cheese and yoghurt), moderate to high consumption of fish and poultry, low consumption of red meat and meat 
products, as well as low to moderate wine consumption. Several nutrients and non-nutrients have been shown to be abundant in the Mediterranean diet pattern, and their possible contributions to decreased mortality due to age-associated diseases have been investigated. However, despite these extensive studies, the role of nutrients such as antioxidants, isoflavone, vitamins, and phytochemicals in preventing disease has not been successfully confirmed. Consequently, the focus has turned to whole diets rather than specific supplements to prevent age-associated diseases, such as cardiovascular disease. $^{7}$

Polyamines (spermine, spermidine, and putrescine) are organic compounds having two or more primary amino groups, are indispensable for cell growth and differentiation, and are contained in almost all cells. Polyamine is absorbed quickly from the intestinal lumen and distributed to all organs and tissues in the body. ${ }^{8-11}$ Because most foods originate from plants or animals, almost all foods contain polyamines, but in widely varying concentrations. ${ }^{12-14}$ Among various foods, beans, especially soybeans, contain abundant polyamines, especially spermine and spermidine. A large number of studies have shown that soybeans contain component(s) that have favorable effects on the progression of chronic age-associated disease, although the identity of these substances remains undefined. ${ }^{15}$

We have shown that spermine and spermidine exert an anti-inflammatory effect by inhibiting the synthesis of proinflammatory cytokines and decreasing exclusively the expression of leukocyte function-associated antigen-1, one of the pivotal molecules needed to elicit immune cell activation and inflammation. ${ }^{16,17}$ Considering the findings that anti-inflammatory substances, such as component(s) of the Mediterranean diet, soybeans, and n-3 unsaturated fatty acid found in fish oil seem to inhibit age-associated diseases, then anti-inflammatory polyamines may have a role in inhibiting the progression of age-associated disease. ${ }^{18-22}$ This is supported by our finding that mice having a long-term intake of chow with polyamine concentrations two to three times higher than that of soybeans had decreased age-associated pathologic changes and increased longevity. ${ }^{23,24}$

\section{Materials and methods}

In order to support the premise that the increased polyamine intake by the Mediterranean diet helps inhibit age-associated diseases and increase human longevity, epidemiologic evidence indicating an association between Mediterranean diet and increased polyamine intake was gathered. Dietary data (levels of food supply in 2005) were obtained from the online database of the Statistics Division of the Food and Agriculture Organization of the United Nations. The target populations were those of 49 countries in Europe, North America, and Oceania (see Figure 1) with similar racial and ethnic composition, as well as social and religious backgrounds.

The food concentrations of spermine, spermidine, and putrescine were obtained from published reports of concentrations measured in European foods. ${ }^{12,13}$ When these reports lacked polyamine concentrations for specific foods, or additional data were necessary to obtain an accurate average concentration in a food, we used data from Nishibori et al. ${ }^{14}$

Because food supply data from the World Health Organization do not necessarily indicate the absolute amount consumed by each nation and in order to capture the features of the dietary pattern, a relative measure of the amount of various foods, such as food supply per total calories, was employed.

The availability of foods in Mediterranean countries and northern European countries was compared by Mann-Whitney $U$ test, with a $P$ value less than 0.05 considered significant. Spearman correlation coefficients were calculated to examine the association between the relative amount of various foods and polyamine amount per calorie. Analyses were done using StatView 5.0 (SAS Institute Inc, Cary, NC) run on an Apple computer, with correlation coefficients of more than 0.4 and $P$ values less than 0.05 considered to be significant.

\section{Results}

The concentrations of three polyamines obtained from published papers and used for the present study are

\footnotetext{
Albania, Armenia, Australia, Austria, Azerbaijan, Belarus, Belgium, Bosnia and Herzegovina, Bulgaria, Canada, Croatia, Cyprus, Czech Republic, Denmark, Estonia, Finland, France, Georgia, Germany, Greece, Hungary, Iceland, Ireland, Israel, Italy, Kazakhstan, Latvia, Lithuania, Malta, The Netherlands, New Zealand, Norway, Poland, Portugal, Romania, Russian Federation, Slovakia, Slovenia, Spain, Sweden, Switzerland, Tajikistan, The former Yugoslav Republic of Macedonia, Turkey, Turkmenistan, Ukraine, United Kingdom, United States of America, Uzbekistan
}

Figure I List of target countries. 
Table I Concentrations of three polyamines in foods ${ }^{\mathrm{a}}$

\begin{tabular}{|c|c|c|c|}
\hline & Spermine & Spermidine & Putrescine \\
\hline Apple ${ }^{b}$ & 0 & 14.73 & 14.27 \\
\hline Banana & 1.00 & 44.90 & 317.30 \\
\hline Lemon and lime & 0.90 & 18.40 & 53.80 \\
\hline Citrus (other) & 0.90 & 18.40 & 53.80 \\
\hline Pineapple & 10.90 & 27.00 & 7.60 \\
\hline Grape $^{c}$ & 1.60 & 22.50 & 26.25 \\
\hline Orange and mandarin ${ }^{d}$ & 0 & 41.40 & 1143.35 \\
\hline Other fruit ${ }^{\mathrm{e}}$ & 3.02 & 25.50 & 11.55 \\
\hline Pulses $^{f}$ & 66.46 & 179.70 & 69.64 \\
\hline Treenuts ${ }^{8}$ & 46.93 & 186.97 & 56.90 \\
\hline Groundnut & 34.60 & 388.70 & 61.40 \\
\hline Cereals $^{\mathrm{h}}$ & 17.94 & 57.55 & 27.29 \\
\hline Potato & 7.90 & 64.70 & 68.73 \\
\hline Maizej & 8.00 & 144.00 & 576.00 \\
\hline Onionk & 2.50 & 41.20 & 38.85 \\
\hline Tomato' & 0 & 19.35 & 380.20 \\
\hline Vegetables $^{m}$ & 6.69 & 124.13 & 52.98 \\
\hline Stimulants ${ }^{n}$ & 12.50 & 61.40 & 18.98 \\
\hline Oil crops & 0 & 0 & 0 \\
\hline Sugar & 0 & 0 & 3.00 \\
\hline Coffee & 0 & 0 & 0 \\
\hline Alcoholic beverages $^{\circ}$ & 0 & 1.00 & 0 \\
\hline Beer $^{p}$ & 0 & 0.50 & 18.60 \\
\hline Wine $^{q}$ & 0 & 2.17 & 26.80 \\
\hline Animal fats & 0 & 0 & 0 \\
\hline Beef & 120.70 & 22.45 & 36.00 \\
\hline Butter and ghee & 0 & 0.50 & 0 \\
\hline Cephalopods s & 86.00 & 13.50 & 82.00 \\
\hline Cheese $^{t}$ & 21.58 & 145.34 & 589.71 \\
\hline Cream & 0 & 0 & 0.30 \\
\hline Crustaceans $^{u}$ & 0 & 1.98 & 4.48 \\
\hline Edible offals ${ }^{\vee}$ & 98.90 & 82.28 & 11.34 \\
\hline Eggs & 0 & 0 & 20.50 \\
\hline Fish $^{w}$ & 16.25 & 16.35 & 61.93 \\
\hline Honey & 0 & 1.00 & 8.00 \\
\hline Meat $^{x}$ & 110.53 & 29.68 & 32.78 \\
\hline Molluscs ${ }^{\gamma}$ & 94.43 & 73.13 & 202.83 \\
\hline Mutton and goat meat & 131.30 & 39.70 & 8.20 \\
\hline Other marine meat ${ }^{z}$ & 37.76 & 25.46 & 82.70 \\
\hline Pork & 160.15 & 18.15 & 19.50 \\
\hline Poultry & 91.70 & 27.50 & 11.43 \\
\hline Whey ${ }^{2 b}$ & 1.00 & 1.00 & 0 \\
\hline Whole milk & 0 & 0 & 0.30 \\
\hline
\end{tabular}

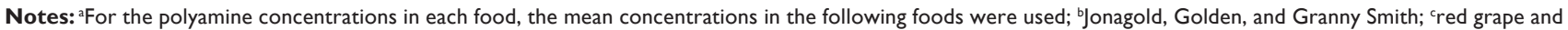
green grape; 'orange and orange'; ' $r a i s i n$, prune, pear, peach, yellow peach, dates, kiwifruit, strawberry, and melon; 'French bean, red bean, garden pea, soyabean', and red kidney bean'; ghazelnut, almond, and pistachio; 'rice, semolina, pasta, white bread, oat bread, rye bread, and whole wheat bread; 'potato skinned, potato with skin, and potato'; 'maize 14 ; 'onion and onion'; 'tomato and tomato'; 'msalsify, celery, carrot, green cabbage, beet, beetroot, carrot, sorrel, radish, chicory, leek, escarole, red cabbage, green leek, Brussels sprout, lettuce, chervil, cabbage, parsley, mushroom, and button mushroom; "garlic, yellow pepper, green pepper, and red pepper; ' whisky and cognac; Plager beer and stout beer; ${ }^{9}$ white (Burgundy), white (Loire), red (Bordeaux), red (Côtes du Rhône), red (Touraine), and red (Beaujolais) wines; 'real and beef; 'squid and octopus ${ }^{14}$; 'soft cheese, Swiss Emmental, French Emmental, goat cheese without rind, Brie pasteurized without rind, graded cheese, Camembert, Brie pasteurized with rind, goat cheese with rind, Roquefort, sweet Cantal with rind, Comte, Saint Nectaire without rind, Saint Nectaire with rind, aged Cheddar', and fresh cheddar'; "scampi, shrimp, crayfish, and crab claw; 'ox tongue, liver mousse, chitterling, duck liver paste, and pork liver paste; whake, cod, whiting, smoked salmon, mullet, fresh salmon, $\operatorname{cod}^{9}$, and trout'; ' veal, pork, turkey, chicken leg, rabbit, lamb, chicken wing, and beef; yoyster, white scallop, coral scallop, and clam ${ }^{14}$; ${ }^{2}$ hake, cod, whiting, smoked salmon, mullet, fresh salmon, $\operatorname{cod}^{9}$, trout ${ }^{9}$, scampi, shrimp, crayfish, crab, squid, octopus ${ }^{14}$, oyster, white scallop, coral scallop, and clam ${ }^{14}$; ${ }^{2 a}$ turkey wing, chicken leg, and chicken wing. ${ }^{2 b}$ No available data, therefore data of matured yoghurt were used. Concentrations of polyamines in foods with no superscript indicate that they were from a single food ${ }^{\prime 3}$. Polyamine concentrations were expressed as $\mathrm{nmol} / \mathrm{g}$ or $\mathrm{mL}$. The amount in fish was a sum of the amounts in freshwater fish, and demersal, pelagic, and other marine fish; the amount in other marine meat was obtained by subtracting the sum of the amounts in fresh water fish, demersal and pelagic fish, other marine fish, crustaceans, molluscs, and cephalopods from the amount in fish and seafood in the FOSTAT database. Aquatic animals and other aquatic products were not consumed in surveyed countries. 
shown in Table 1. These concentrations differed considerably among foods. Basically, meat and some seafood contained relatively large amounts of spermine and spermidine, and several fruit and vegetables contained relatively large amounts of spermidine and putrescine. While whole milk had few polyamines, cheese contained a large amount.

To test whether the data showed that increased amounts of Mediterranean diet foods were preferred in Mediterranean countries, food amounts relative to calorie amounts were compared between Mediterranean and northern Europe. As shown in Table 2, greater amounts of olive oil, legumes, vegetables, and fruit and vegetables are preferred in Mediterranean countries compared with northern European countries. In addition, although no significance was observed, Mediterranean countries tend to prefer cheese

Table 2 Comparison of foods between Mediterranean countries and northern European countries ${ }^{\mathrm{a}}$

\begin{tabular}{|c|c|c|c|}
\hline & $\begin{array}{l}\text { Mediterranean } \\
\text { countries }\end{array}$ & $\begin{array}{l}\text { Northern } \\
\text { countries }\end{array}$ & $P$ value \\
\hline Olive oil/total calories & $8.34 \pm 4.81$ & $0.47 \pm 0.37$ & 0.003 \\
\hline $\begin{array}{l}\text { Percent olive } \\
\text { oil/total fat }\end{array}$ & $19.58 \pm 11.76$ & $1.19 \pm 0.92$ & 0.005 \\
\hline $\begin{array}{l}\text { Percent animal } \\
\text { fat/total fat }\end{array}$ & $44.00 \pm 8.70$ & $58.76 \pm 4.79$ & 0.017 \\
\hline Legumes/total calories & $3.16 \pm 1.13$ & $1.36 \pm 0.78$ & 0.017 \\
\hline Fruit/total calories & $105.36 \pm 26.89$ & $85.83 \pm 23.48$ & 0.257 \\
\hline $\begin{array}{l}\text { Vegetables/total } \\
\text { calories }\end{array}$ & $140.94 \pm 36.70$ & $73.77 \pm 13.44$ & 0.003 \\
\hline $\begin{array}{l}\text { Fruit and } \\
\text { vegetables/total } \\
\text { calories }\end{array}$ & $246.30 \pm 31.31$ & $159.60 \pm 20.20$ & 0.007 \\
\hline Wheat/total calories & $91.24 \pm 18.42$ & $75.00 \pm 17.14$ & 0.089 \\
\hline Potato/total calories & $48.00 \pm 12.59$ & $77.67 \pm 21.51$ & 0.017 \\
\hline Cheese/total calories & $14.70 \pm 6.75$ & $11.61 \pm 5.93$ & 0.497 \\
\hline $\begin{array}{l}\text { Dairy products/total } \\
\text { calories }\end{array}$ & $182.67 \pm 33.94$ & $227.60 \pm 49.71$ & 0.141 \\
\hline $\begin{array}{l}\text { Whole milk/total } \\
\text { calories }\end{array}$ & $54.76 \pm 23.62$ & $87.87 \pm 32.50$ & 0.070 \\
\hline $\begin{array}{l}\text { Percent cheese/dairy } \\
\text { products }\end{array}$ & $7.67 \pm 2.77$ & $5.09 \pm 2.53$ & 0.113 \\
\hline Seafood/total calorie & $23.72 \pm 8.34$ & $24.76 \pm 17.54$ & 0.651 \\
\hline $\begin{array}{l}\text { Percent seafood and } \\
\text { poultry/red meat }\end{array}$ & $67.62 \pm 13.19$ & $83.70 \pm 30.59$ & 0.308 \\
\hline Wine/total calories & $30.93 \pm 9.42$ & $1 \mathrm{I} .60 \pm 5.88$ & 0.006 \\
\hline Beer/total calories & $32.88 \pm 20.13$ & $69.47 \pm 5.72$ & 0.017 \\
\hline $\begin{array}{l}\text { Other alcoholic } \\
\text { drinks/total calories }\end{array}$ & $1.91 \pm 1.05$ & $5.17 \pm 3.13$ & 0.017 \\
\hline
\end{tabular}

Notes: ${ }^{a}$ Data represent mean \pm standard deviation; 'France, Spain, Italy, and Greece; 'Denmark, Estonia, Finland, Germany, Iceland, Ireland, Latvia, Lithuania, Netherlands, Norway, Russian Federation, Sweden, and UK. Legumes, fruits, vegetables, wheat, potato, cheese, dairy products, and seafood amounts are expressed in $\mu$ g. Olive oil, whole milk, wine, beer, and other alcoholic drink amounts are expressed in $\mu \mathrm{L}$. rather than whole milk, and wheat (cereals) rather than potatoes. While beer and other alcoholic beverages were preferred in northern European countries, wine was preferred in Mediterranean countries. Compared with those in Mediterranean countries, people in northern European countries had a significant preference for foods that are absent from the Mediterranean diet, such as animal fat and potatoes.

The association between the relative amount of Mediterranean diet foods and polyamines per calorie was evaluated for the 49 Western countries. As shown in Table 3, polyamine amount per calorie was significantly associated with the amount of olive oil, fruit and vegetables, seafood, and cheese relative to total calories supplied. Although their correlation coefficients were less than 0.4 , the following ratios (legumes to total calories consumed, seafood and poultry to red meat, seafood fat to total fat, wine to total calories consumed) had a trend of positive association with polyamine amount per calorie with $P$ values less than 0.05 .

Table 3 Correlation between polyamine and foods

\begin{tabular}{|c|c|c|}
\hline & $\begin{array}{l}\text { Spearman's correlation } \\
\text { coefficient }\end{array}$ & $P$ value \\
\hline \multicolumn{3}{|l|}{ Mediterranean diet foods } \\
\hline Olive oil/total calories & 0.602 & $<0.001$ \\
\hline Olive oil/total fat & 0.612 & $<0.001$ \\
\hline Legumes/total calories & 0.379 & 0.009 \\
\hline Legumes/crops calories & 0.395 & 0.006 \\
\hline Fruit/total calories & 0.804 & $<0.001$ \\
\hline $\begin{array}{l}\text { Fruit and vegetables/total } \\
\text { calories }\end{array}$ & $0.6 \mathrm{II}$ & $<0.001$ \\
\hline Wheat/total calories & -0.287 & 0.047 \\
\hline $\begin{array}{l}\text { Seafood calories/total } \\
\text { calories }\end{array}$ & 0.461 & 0.001 \\
\hline $\begin{array}{l}\text { Seafood and poultry } \\
\text { meat/red meat }\end{array}$ & 0.313 & 0.030 \\
\hline Cheese/total calories & $0.4 \mathrm{II}$ & 0.005 \\
\hline Seafood fat/total fat & 0.391 & 0.007 \\
\hline Wine/total calories & 0.285 & 0.049 \\
\hline \multicolumn{3}{|l|}{ Non-Mediterranean diet foods } \\
\hline Potato/total calories & -0.078 & 0.586 \\
\hline Animal fat/total fat & -0.004 & 0.980 \\
\hline Whole milk/total calories & -0.323 & 0.025 \\
\hline Whole milk/dairy products & -0.351 & 0.015 \\
\hline Beer/total calories & -0.013 & 0.927 \\
\hline $\begin{array}{l}\text { Other alcoholic } \\
\text { drink/total calories }\end{array}$ & -0.136 & 0.345 \\
\hline
\end{tabular}

Notes: Spearman's correlation coefficients were calculated to examine the association between the relative amount of various foods and polyamine intake per calories. Correlation coefficients of more than 0.4 and a $P$ value less than 0.05 were considered significant. Mediterranean diet foods indicate the typical foods of which consumption were reported to be higher in Mediterranean countries than non-Mediterranean countries. 
Among the Mediterranean diet foods, only the ratio of wheat to total calories had a trend of negative association with polyamine amount. In spite of the positive association between cheese and polyamine amount, the ratio of whole milk to total calories and whole milk to dairy products had a trend of negative association with polyamine amount $(P$ value less than 0.05 ).

Because our previous experiments showed that spermine has the most potent biologic activity among natural polyamines, ${ }^{17}$ this analysis was done using spermine amount per calorie instead of total polyamine per calorie. As shown in Table 4, the results were similar to those in Table 3. Namely, spermine amount per calorie was significantly associated with supply of many Mediterranean diet foods, such as olive oil, fruit, seafood, cheese, and wine, relative to total calories. Again, despite the positive association between cheese and spermine amount, the ratio of whole milk to total calories and whole milk to dairy products had a negative association with spermine amount.

Table 4 Correlation between spermine and foods

\begin{tabular}{|c|c|c|}
\hline & $\begin{array}{l}\text { Spearman's } \\
\text { correlation coefficient }\end{array}$ & $P$ value \\
\hline \multicolumn{3}{|l|}{ Mediterranean diet foods } \\
\hline Olive oil/total calories & 0.608 & $<0.001$ \\
\hline Olive oil/total fat & 0.579 & $<0.001$ \\
\hline Legumes/total calories & 0.270 & 0.153 \\
\hline Legumes/crops calories & 0.226 & 0.117 \\
\hline Fruit/total calories & 0.491 & $<0.001$ \\
\hline $\begin{array}{l}\text { Fruit and vegetables/total } \\
\text { calories }\end{array}$ & 0.107 & 0.459 \\
\hline Wheat/total calories & -0.579 & $<0.001$ \\
\hline $\begin{array}{l}\text { Seafood calories/total } \\
\text { calories }\end{array}$ & 0.587 & $<0.001$ \\
\hline $\begin{array}{l}\text { Seafood and poultry } \\
\text { meat/red meat }\end{array}$ & 0.140 & 0.334 \\
\hline Cheese/total calories & 0.550 & $<0.001$ \\
\hline Seafood fat/total fat & 0.490 & $<0.001$ \\
\hline Wine/total calories & 0.511 & $<0.001$ \\
\hline \multicolumn{3}{|l|}{ Non-Mediterranean diet foods } \\
\hline Potato/total calories & -0.100 & 0.487 \\
\hline Animal fat/total fat & 0.160 & 0.267 \\
\hline Whole milk/total calories & -0.482 & $<0.001$ \\
\hline Whole milk/dairy products & -0.557 & $<0.001$ \\
\hline Beer/total calories & 0.464 & 0.001 \\
\hline $\begin{array}{l}\text { Other alcoholic } \\
\text { drink/total calories }\end{array}$ & 0.003 & 0.984 \\
\hline
\end{tabular}

Notes: Spearman's correlation coefficients were calculated to examine the association between the relative amount of various foods and spermine intake per calories. Correlation coefficients of more than 0.4 and a $P$ value less than 0.05 were considered statistically significant. Mediterranean diet foods indicate typical foods of which consumption were reported to be higher in Mediterranean countries than in non-Mediterranean countries.

\section{Discussion}

The present epidemiologic study using data collected from an open database produced results similar to those of previous reports. ${ }^{4-6}$ Namely, in Mediterranean countries, olive oil, legumes, fruit and vegetables, cheese, and wine are consumed in preference to animal fat, potatoes, and whole milk. Unfortunately, some of the data relevant to the Mediterranean diet, such as the amount of unrefined cereals and yoghurt, especially low-fat yoghurt, could not be obtained. Also, there was no between-region difference in the supply of a few Mediterranean diet foods per total calories, such as seafood and poultry relative to red meat. However, this epidemiologic study using an open database revealed that most Mediterranean diet foods are preferred in Mediterranean countries relative to northern European countries.

There is increasing evidence that following a Mediterranean diet correlates with greater longevity and delays the onset of age-associated health deterioration, not only in Mediterranean countries but also in non-Mediterranean countries. ${ }^{25,26}$ Although many studies have focused on particular food substances in the Mediterranean diet that are responsible for maintaining human health, the results have not been adequately confirmed. As shown in the previous reports and in Table 1, polyamines are contained in most foods in widely varying concentrations, ${ }^{12,13}$ therefore differences in dietary pattern greatly influence the amount of polyamine intake. As expected, most Mediterranean diet food consumption is associated with increased polyamine amount.

Among the mechanisms that account for the protective effect of the Mediterranean diet against age-associated health deterioration is that the Mediterranean diet seems to have a protective effect against mild chronic inflammation and its metabolic complications. ${ }^{18-20,27,28}$ Similar to n-3 unsaturated fatty acids, which have been shown to decrease age-associated health deterioration, ${ }^{29,30}$ polyamine, especially spermine, has an anti-inflammatory effect by suppressing inflammatory mediators. ${ }^{16,17}$ In addition, an increase in intracellular polyamines from extracellular sources seems to help maintain vascular health. The increase in intracellular polyamines suppresses enzymatic activities needed for polyamine synthesis. Because polyamines are synthesized from arginine, this suppression could increase the amount of arginine available for nitric oxide synthesis. Decreased bioavailability of nitric oxide is involved in the pathogenesis of various disorders, ${ }^{31}$ and, 
conversely, increased nitric oxide maintains normal vascular function. ${ }^{32,33}$ Therefore, continuously increased polyamine intake from foods increases nitric oxide availability and helps slow the progression of age-associated vascular disorders, which are the biggest killer of adults in European and Western countries.

This is an epidemiologic study, so there may be confounding factor(s) between the amount of polyamine and the Mediterranean diet foods. Moreover, polyamine content in food is affected by the effects of food processing and storage, and one of the weaknesses of the present study was the inability to comprehend these changes. ${ }^{32,33}$ However, the present findings, together with previous studies on polyamines, ${ }^{23}$ indicate a possible role for the food polyamines that are abundant in the Mediterranean diet in prolonging human life.

\section{Disclosure}

This research received no specific grant from any funding agency in the public, commercial, or not-for-profit sectors.

\section{References}

1. Bamia C, Trichopoulos D, Ferrari P, et al. Dietary patterns and survival of older Europeans: The EPIC-Elderly Study (European Prospective Investigation into Cancer and Nutrition). Public Health Nutr. 2007; 10(6):590-598.

2. Iestra J, Knoops K, Kromhout D, de Groot L, Grobbee D, van Staveren W. Lifestyle, Mediterranean diet and survival in European post-myocardial infarction patients. Eur J Cardiovasc Prev Rehabil. 2006;13(6):894-900.

3. Lagiou P, Trichopoulos D, Sandin S, et al. Mediterranean dietary pattern and mortality among young women: A cohort study in Sweden. Br J Nutr. 2006;96(2):384-392.

4. Keys A, Menotti A, Karvonen MJ, et al. The diet and 15-year death rate in the seven countries study. Am J Epidemiol. 1986;124(6): 903-915.

5. Tunstall-Pedoe H, Kuulasmaa K, Mahonen M, Tolonen H, Ruokokoski E, Amouyel P. Contribution of trends in survival and coronary-event rates to changes in coronary heart disease mortality: 10-year results from 37 WHO MONICA project populations. Monitoring trends and determinants in cardiovascular disease. Lancet. 1999;353(9164): 1547-1557.

6. Masia R, Pena A, Marrugat J, et al. High prevalence of cardiovascular risk factors in Gerona, Spain, a province with low myocardial infarction incidence. REGICOR Investigators. J Epidemiol Community Health. 1998;52(11):707-715.

7. Lichtenstein AH, Appel LJ, Brands M, et al. Summary of American Heart Association Diet and Lifestyle Recommendations Revision 2006. Arterioscler Thromb Vasc Biol. 2006;26(10):2186-2191.

8. Nishimura K, Araki N, Ohnishi Y, Kozaki S. Effects of dietary polyamine deficiency on Trypanosoma gambiense infection in rats. Exp Parasitol. 2001;97(2):95-101.

9. Bardocz S, Duguid TJ, Brown DS, et al. The importance of dietary polyamines in cell regeneration and growth. Br J Nutr. 1995;73(6): 819-828.

10. Uda K, Tsujikawa T, Fujiyama Y, Bamba T. Rapid absorption of luminal polyamines in a rat small intestine ex vivo model. J Gastroenterol Hepatol. 2003;18(5):554-559.
11. Kobayashi M, Xu YJ, Samejima K, et al. Fate of orally administered $15 \mathrm{~N}$-labeled polyamines in rats bearing solid tumors. Biol Pharm Bull. 2003;26(3):285-288.

12. Bardócz S, Grant G, Brown DS, Ralph A, Pusztai A. Polyamines in food - implications for growth and health. J Nutr Biochem. 1993; 4(2):66-71.

13. Cipolla BG, Havouis R, Moulinoux JP. Polyamine contents in current foods: A basis for polyamine reduced diet and a study of its long term observance and tolerance in prostate carcinoma patients. Amino Acids. 2007;33(2):203-212.

14. Nishibori N, Fujihara S, Akatuki T. Amounts of polyamines in foods in Japan and intake by Japanese. Food Chem. 2007;100(2): 491-497.

15. Sacks FM, Lichtenstein A, van Horn L, Harris W, Kris-Etherton P, Winston M. Soy protein, isoflavones, and cardiovascular health: An American Heart Association Science Advisory for professionals from the Nutrition Committee. Circulation. 2006;113(7): 1034-1044.

16. Zhang M, Caragine $\mathrm{T}$, Wang $\mathrm{H}$, et al. Spermine inhibits proinflammatory cytokine synthesis in human mononuclear cells: A counterregulatory mechanism that restrains the immune response. J Exp Med. 1997;185(10):1759-1768.

17. Soda K, Kano Y, Nakamura T, Kasono K, Kawakami M, Konishi F. Spermine, a natural polyamine, suppresses LFA-1 expression on human lymphocyte. J Immunol. 2005;175(1):237-245.

18. Esposito K, Marfella R, Ciotola M, et al. Effect of a Mediterraneanstyle diet on endothelial dysfunction and markers of vascular inflammation in the metabolic syndrome: A randomized trial. JAMA. 2004;292(12):1440-1446.

19. Chrysohoou C, Panagiotakos DB, Pitsavos C, Das UN, Stefanadis C. Adherence to the Mediterranean diet attenuates inflammation and coagulation process in healthy adults: The ATTICA Study. J Am Coll Cardiol. 2004;44(1):152-158.

20. Lopez-Garcia E, Schulze MB, Fung TT, et al. Major dietary patterns are related to plasma concentrations of markers of inflammation and endothelial dysfunction. Am J Clin Nutr. 2004;80(4):1029-1035.

21. Satsu H, Hyun JS, Shin HS, Shimizu M. Suppressive effect of an isoflavone fraction on tumor necrosis factor-alpha-induced interleukin-8 production in human intestinal epithelial Caco-2 cells. J Nutr Sci Vitaminol (Tokyo). 2009;55(5):442-446.

22. Calder PC. n-3 polyunsaturated fatty acids, inflammation, and inflammatory diseases. Am J Clin Nutr. 2006;83 Suppl 6:S1505-S1519.

23. Soda K, Dobashi Y, Kano Y, Tsujinaka S, Konishi F. Polyamine-rich food decreases age-associated pathology and mortality in aged mice. Exp Gerontol. 2009;44(11):727-732.

24. Soda K, Kano Y, Sakuragi M, Takao K, Lefor A, Konishi F. Long-term oral polyamine intake increases blood polyamine concentrations. J Nutr Sci Vitaminol (Tokyo). 2009;55(4):361-366.

25. Kouris-Blazos A, Gnardellis C, Wahlqvist ML, Trichopoulos D, Lukito W, Trichopoulou A. Are the advantages of the Mediterranean diet transferable to other populations? A cohort study in Melbourne, Australia. Br J Nutr. 1999;82(1):57-61.

26. Haveman-Nies A, de Groot LC, van Staveren WA. Dietary quality, lifestyle factors and healthy ageing in Europe: The SENECA study. Age Ageing. 2003;32(4):427-434.

27. Estruch R, Martinez-Gonzalez MA, Corella D, et al. Effects of a Mediterranean-style diet on cardiovascular risk factors: A randomized trial. Ann Intern Med. 2006;145(1):1-11.

28. Schulze MB, Hoffmann K, Manson JE, et al. Dietary pattern, inflammation, and incidence of type 2 diabetes in women. Am J Clin Nutr. 2005;82(3):675-684.

29. Lee TH, Hoover RL, Williams JD, et al. Effect of dietary enrichment with eicosapentaenoic and docosahexaenoic acids on in vitro neutrophil and monocyte leukotriene generation and neutrophil function. N Engl J Med. 1985;312(19):1217-1224. 
30. Mehta JL, Lopez LM, Lawson D, Wargovich TJ, Williams LL. Dietary supplementation with omega-3 polyunsaturated fatty acids in patients with stable coronary heart disease. Effects on indices of platelet and neutrophil function and exercise performance. Am J Med. 1988;84(1):45-52.

31. Lefer AM, Lefer DJ. The role of nitric oxide and cell adhesion molecules on the microcirculation in ischaemia-reperfusion. Cardiovasc Res. 1996;32(4):743-751.
32. Drexler H, Zeiher AM, Meinzer K, Just H. Correction of endothelial dysfunction in coronary microcirculation of hypercholesterolaemic patients by L-arginine. Lancet. 1991;338(8782-3):1546-1550.

33. Cooke JP, Singer AH, Tsao P, Zera P, Rowan RA, Billingham ME. Antiatherogenic effects of L-arginine in the hypercholesterolemic rabbit. J Clin Invest. 1992;90(3):1168-1172.

\section{Publish your work in this journal}

Nutrition and Dietary Supplements is an international, peer-reviewed, open access journal focusing on research into nutritional requirements in health and disease, impact on metabolism and the identification and optimal use of dietary strategies and supplements necessary for normal growth and development. The journal welcomes papers covering original research, basic science, clinical \& epidemiological studies, reviews and evaluations, guidelines, expert opinion and commentary, case reports and extended reports. The manuscript management system is completely online and includes a very quick and fair peer-review system, which is all easy to use.

Submit your manuscript here: http://www.dovepress.com/nutrition-and-dietary-supplements-journal 